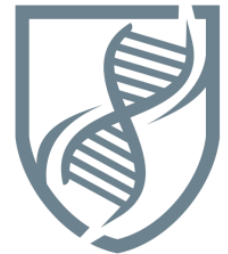

Journal of Bioscience and Applied Research

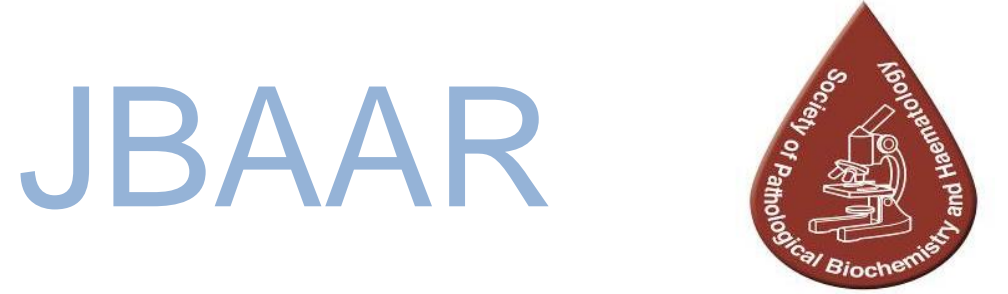

WWW.JBAAR.ORG

\title{
The possible anti-inflammatory role of the blue-green algae, Aphanizomenon flos-aquae on the skin of adult male rats
}

\author{
Hemmat Mansour Abdelhafez and Rasha Mohammed Ibrahim \\ Department of Zoology, Faculty of Science, Al- Azhar University, Cairo, Egypt. \\ DOI: $10.21608 /$ JBAAR.2018.129862
}

\begin{abstract}
Aphanizomenon flose-aquae (AFA) is a freshwater unicellular blue-green microalga like Spirulina, but most AFA is harvested from the wild in volcanic regions leading to high levels of trace minerals. It has been traditionally used for over 25 years for its health-enhancing properties. Aphanizomenon flos-aquae is an important source of the blue photosynthetic pigment phycocyanin (PC), which has been described as a strong antioxidant and antiinflammatory agent. Aim of the study: this study aimed to examine the possible anti-inflammatory effect of AFA against the inflammation induced by carrageenan injection on the skin of adult male rats using histopathological and histochemical studies. Material and methods: the current experiment was carried out on 48 adult male albino rats (Rattus rattus). Rats were randomly and equally categorized into four groups: 1) Control group (C): rats were left without treatment; 2) Carr group: rats were injected with carrageenan and left for 21 days ; 3) AFA group: rats were orally administrated Aphanizomenon flosaquae (AFA) extract $(94.5 \mathrm{mg} / \mathrm{kg}$ body weight /day) for 21 days and 4) AFA+ Carr Group: rats were injected with carrageenan and treated with $94.5 \mathrm{mg} / \mathrm{kg}$ body weight AFA extract daily after six hours of carrageenan injection for 21 days. The experimental rats were sacrificed after 5 and 21 days post-treatment._ Results: Examination of skin tissue of rats five and twenty-one day's post-carrageenan injection revealed many histopathological and histochemical changes such as marked destructed epidermal and dermal layers. The epidermal layer showed undetectable cellular structure, thickened keratin layer. Signs of fibrosis and absence of hair follicles were detected in some areas, in addition to the presence of debris of degenerated cells in the dermal layer. Hair follicles were distorted with numerous fibroblasts in the dermal layer, some of them were hypertrophied, in addition to the presence of a large granulomatous area in the dermal layer, discontinuous and faintly stained skeletal muscle fibres were noticed. Most of them showed decreased staining
\end{abstract}

the affinity of nuclei of mycocytes (karyolysis) with signs of fatty degeneration. Highly increased collagen fibres and fibrotic areas were detected in the epidermal and dermal layers.

Skin tissues examined five and twenty-one days following AFA administration showed normal appearance of the epidermal and dermal layers, highly increased and well-developed hair follicles with their sebaceous glands were detected with normal distribution to some extent, of collagen fibres.

Skin tissues of rats administrated with AFA for twentyone days post-carrageenan injection and examined after five and twenty-one days showed striking recovery as compared to the skin of carrageenan group only, but increased collagen fibres in the dermal layer were detected after five days while the normal distribution of collagen fibres was demonstrated after twenty-one days.

The quantitative histochemical measurements recorded a significant increase in PAS+ve materials, total protein, and amyloid $\beta$-protein in the carrageenan injected group while supplementation with AFA alone or AFA post carrageenan injection showed a trend toward lowering the incidence of skin histochemical changes induced by carrageenan injection. Skin tissues of the carrageenan group showed a significant increase in mast cell count in the dermal layer after five and twenty-one days posttreatment. AFA treated group exhibited a non-significant increase of mast cells in the dermal layer all over the experimental periods, while rats administrated AFA postcarrageenan injection exhibited a significant increase in the count of mast cells after five days and a non-significant increase after twenty-one days Conclusion: using Aphanizomenon flos- aquae as a natural agent exerted a marked anti-inflammatory role against the histopathological and histochemical lesions induced by carrageenan injection. Keywords: carrageenan, Aphanizomenon flos- aquae, inflammation, and rats. 


\section{Introduction}

Carrageenan emerged as a fascinating compound that has a wide spectrum of interference with the biological systems. Although the safety and toxicity profile of carrageenan is well studied, it was reported that different carrageenan subtypes (iota-, lambda- and kappa-carrageenan) can produce different biological and toxicological effects (Mckim, 2014). The edema induced by carrageenan is due, in part, to the liberation of bioamines. During the first hour, the principal agents implicated in the edema formation are the bioamines histamine, serotonin, and the peptide bradykinin. These are followed in time by prostaglandins, which are the principal mediators involved in the increased vascular permeability together with nitric-oxid, which is formed by leukocytes, endothelial cells, and sensory nerve cells at the site of inflammation. In the acute phase, the increase in vascular permeability produces cell infiltration, mainly neutrophils, increasing the inflammatory response after the production of oxygen-derived species (Dash and Kanungo, 2013).

Inflammation is a complex cellular and biochemical response to injurious stimuli that involve many cytokines and inflammatory mediators. It is a normal essential protective response to any noxious stimulus that may threaten the body and may differ from a localized reaction to a complex response involving the whole organism(Cotran et al., 2004). Agents that modify inflammatory responses are called anti-inflammatory drugs. Non-steroidal anti-inflammatory drugs (NSAID) are generally used to treat acute and chronic inflammatory conditions. However, due to their adverse side-effects and increased cardiovascular disease (CVD) risk is associated with chronic use of several NSAIDs (Jugdutt, 2007); there is a critical need to identify natural products with antiinflammatory properties.

There is a worldwide trend to natural resources, which are culturally acceptable and economically viable. Among the important and effective drugs used to treat chronic diseases are derived from plants and certain species of cyanobacteria (Nahin et al., 2009; El-Depsi, 2016). Blue-green algae (BGA), also known as cyanobacteria, among the phylum of bacteria that utilize photosynthesis to obtain energy.
They are technically classified as bacteria and share properties with them (Schaap et al., 2012). Selmi $\boldsymbol{e t}$ al. (2011) demonstrated that BGA consumption protects against inflammatory diseases and promotes immunity. They are nutritious natural products rich in essential amino acids, $\gamma$-linolenic acid, B vitamins, fibres, calcium, phosphorous, iron, pigments such as $\beta$-carotene, xanthophylls, chlorophyll, and other bioactive compounds (Regunathan and Wesley, 2006). Singh et al. (2005) and El-Depsi (2016) reported that BGA has antiviral, antitumor, antioxidant, anti-inflammatory, anti-allergic, antidiabetic, and antibacterial properties as well as lipidlowering effects. Aphanizomenon flos-aquae (AFA) is a freshwater unicellular blue-green alga that is consumed as a nutrient-dense food source and for its health-enhancing properties (Scoglio et al., 2014). Aphanizomenon flos-aquae as a species has both nontoxic and toxic forms. Most

sources worldwide are toxic, containing both hepatic and neuroendotoxins. Aphanizomenon flos-aquae from Klamath Lake is a non-toxic type of algae of the cyanobacteria phylum (Jensen et al., 2001). Aphanizomenon flos-aquae has gained popularity in the USA, Germany, Canada, Korea, Japan, and Austria. It contains 20 antioxidants, 68 minerals, 70 trace elements, all amino acids, B vitamins, and important enzymes (Chakdar et al., 2012). Also, the most common BGA, Spirulina platensis (SP) and Aphanizomenon flos-aquae (AFA) were found to have antioxidant (Venkatesan et al., 2012), antiinflammatory, and hypolipidemic properties (Yang $\boldsymbol{e t}$ al., 2011). Aphanizomenon flos-aquae is an important source of the blue photosynthetic pigment phycocyanin (PC), which has been described as a strong antioxidant and anti-inflammatory agent (Benedetti et al., 2010). Moreover, carotenoids can serve as a marker for the whole antioxidant status of the human epidermis (Haag et al., 2013).

\section{Material and Methods}

\section{Experimental animals}

A total of forty-eight mature male albino rats weighing about 120-160 g. each were used in the present study. The animals were kept in the laboratory 
for two weeks before the experimental work. They were housed in specially designed and cleaned cages, 6 rats per cage, and maintained under controlled conditions of temperature, light (12 hours light: 12 hours dark), and good ventilation. They were fed a normal diet and water ad libitum.

\section{Experimental design}

The experimental animals were divided into 4 groups:

Group 1- Untreated normal control rats (C).

Group 2- Rats were injected with carrageenan and left for 21 days (Carr).

Group3-Rats were orally administrated Aphanizomenon flos- aquae (AFA) extract ( $94.5 \mathrm{mg} / \mathrm{kg}$ body weight /day) for 21 days.

Group 4- Rats were injected with carrageenan and treated with $94.5 \mathrm{mg} / \mathrm{kg}$ body weight AFA extract daily after 6 hours of carrageenan injection for 21 days (AFA+ Carr).

The experimental rats were sacrificed after 5 and 21 days post-treatment.

\section{Inflammatory model (rat paw edema)}

Carrageenan (Carr) was obtained from Sigma Company. Type IVEC No. 232-953-5. Carrageenan solution was prepared as $1 \%$ suspension in saline, where each animal was injected with $0.1 \mathrm{ml}$ of carrageenan solution in sub planter tissue of the left hind paw (Ghosh et al., 2000) for induction of experimental inflammation. Preparation of Aphanizomenon flos-aquae (AFA) extract

AFA-Klamath capsules $(350 \mathrm{mg}$ ) were purchased from the German Egyptian Pharmaceutical Company. AFA capsules were opened and dissolved in distilled water. The drug was administrated orally by gastric tube at a dose of $94.5 \mathrm{mg} / \mathrm{kg}$ body weight/day for 21 days. The dose for the rat was calculated according to Paget's formula based on the human dose (Paget and Barns, 1964).

\section{-Histopathological and histochemical techniques}

The skin of the foot paw of all groups was washed in saline and fixed in 10\% neutral formalin, followed by dehydration in ascending grades of alcohol, cleared in xylene, and embedding in paraffin wax. Sections were then cut at $5 \mu$ thickness and stained by hematoxylin and eosin for histopathological study according to the method of Bancroft and Gamble
(2002). Collagen fibres were stained by Mallory's trichrome (Pears, 1977). Polysaccharides were detected by using periodic acid Schiff's (PAS) reagent (Drury and Wallington, 1980). Total proteins could be visualized by the mercuric bromophenol blue method (Mazia et al., 1953). Mast cells were stained by toluidine blue (Sheehan and Hrapchak, 1980). Amyloid- $\beta$ protein was detected by Congo red technique (Valle, 1986).

\section{Quantitative histochemical analysis}

The optical density of histochemically stained sections in skin tissue for carbohydrates, total protein, and Amyloid- $\beta$ protein of the control and treated groups as well as a count of mast cells were recorded using IPWIN 32 image analysis software.

\section{Statistical analysis}

Statistical analyses were performed using analyses of variance (ANOVA) according to Snedecor and Cochran (1980). The data were processed and analyzed using the SPSS software (Statistical Analysis for Social Science, Version 8). Significant differences between treatment means were determined by student t-test. Data were presented as mean $\pm \mathrm{SE}$ and $\mathrm{P}<0.05$ was considered statistically significant.

\section{Results}

\section{Histopathological and histochemical observation}

\section{The control group}

The normal structure of the leg skin of a control rat is demonstrated in figs. 1 and 2. The skin is mainly formed of the following layers

1- Epidermis, an epithelial layer formed of the stratified keratinized squamous epithelium of ectodermal origin.

2- Dermis, a connective tissue layer of mesodermal origin. The dermis containing hair follicles, glands, and receptors. A subcutaneous connective tissue layer (hypodermis) is found.

The normal distribution of collagen fibres in the epidermal and dermal layers is shown in figs. 3 and 4. Thin collagen fibres are supporting the epidermal and dermal layers.

\section{Carrageenan injected group}

Examination of skin tissue of rats five days postcarrageenan injection showed completely degenerated epidermal and dermal layers. 
The epidermal layer showed undetectable cellular structure, thickened keratin layer with highly affected and distorted epidermal layer. Signs of fibrosis and absence of hair follicles were detected in some areas, in addition to the presence of debris of degenerated cells in the dermal layer. Hair follicles were distorted with numerous fibroblasts in the dermal layer, some of them were hypertrophied, in addition to the presence of a large granulomatous area (Figs. 5-8).

By the end of twenty-one days following carrageenan injection, marked destructed epidermal and dermal layers were detected, in addition to the absence of the cellular structure of the corrugated epidermal layer. Highly distorted and reduced hair follicles with ruptured, discontinuous, and faintly stained skeletal muscle fibres were noticed. Most of them showed decreased staining affinity of nuclei of mycocytes (karyolysis) with signs of fatty degeneration (Figs. 11-15).

Concerning the distribution of collagen fibres, highly increased collagen fibres and fibrotic areas were detected in the epidermal and dermal layers after 5 (Figs.9, 10) and 21 days (Figs. 16, 17).

\section{AFA-treated group}

Skin tissues examined five and twenty-one days following AFA administration showed normal appearance of the epidermal and dermal layers, highly increased and well-developed hair follicles with their sebaceous glands were detected(Figs. 18,19) with a normal distribution of collagen fibres (Figs. 20,21).

\section{Group treated with AFA post-carrageenan injection}

Skin tissues of rats administrated with AFA for twenty-one days post-carrageenan injection and examined after five and twenty-one days showed striking recovery as compared to the skin of carrageenan group only, but increased collagen fibres in the dermal layer were detected after five days (Figs. 22, 23, 25).

As shown in Fig. 24 and 26 epidermal and dermal layers were resuming their normal structure after twenty-one days with highly increased and welldeveloped hair follicles in the expanded dermal layer and a somewhat normal distribution of collagen fibres could be demonstrated.

\section{Quantitative histochemical measurements}

The present study revealed that the group of rats injected with carrageenan exhibited a significant increase in the mean value of PAS-positive materials all over the experimental periods. While rats administrated AFA alone or AFA post-carrageenan injection exhibited a non-significant increase in the mean value of PAS-positive materials relative to the control group after five and twenty-one days posttreatment. The Carrageenan group exhibited a significant increase in the mean value of total protein while the group treated with AFA alone exhibited a non-significant increase in the mean value of total protein all over the experimental periods. Rats administrated AFA post-carrageenan injection induced a significant increase in the mean value of total protein after five days while a nonsignificant increase after twenty-one days could be recorded. Carrageenan group showed a significant increase in the mean value of amyloid $\beta$-protein content in skin tissue relative to the control group all over the experimental periods while, rats administrated AFA alone or AFA post-carrageenan injection induced a non-significant change in the mean value of amyloid $\beta$-protein during the two experimental periods.

\section{Mast cells count}

Figures 52- 58 illustrated the changes in the count of mast cells in sections of the skin of the control(Fig. 52) and treated groups after five and twenty-one days post-treatment. Skin sections of the carrageenan group showed a significant increase in the count of mast cells in the dermal layer after five and twentyone days post-treatment (Figs. 53,54). AFA treated group exhibited a non-significant increase of mast cells in the dermal layer all over the experimental periods(Figs. 55,56), while rats administrated AFA post-carrageenan injection exhibited a significant increase in the count of mast cells after five days and a non-significant increase after twenty-one days (Figs. 57-58). 

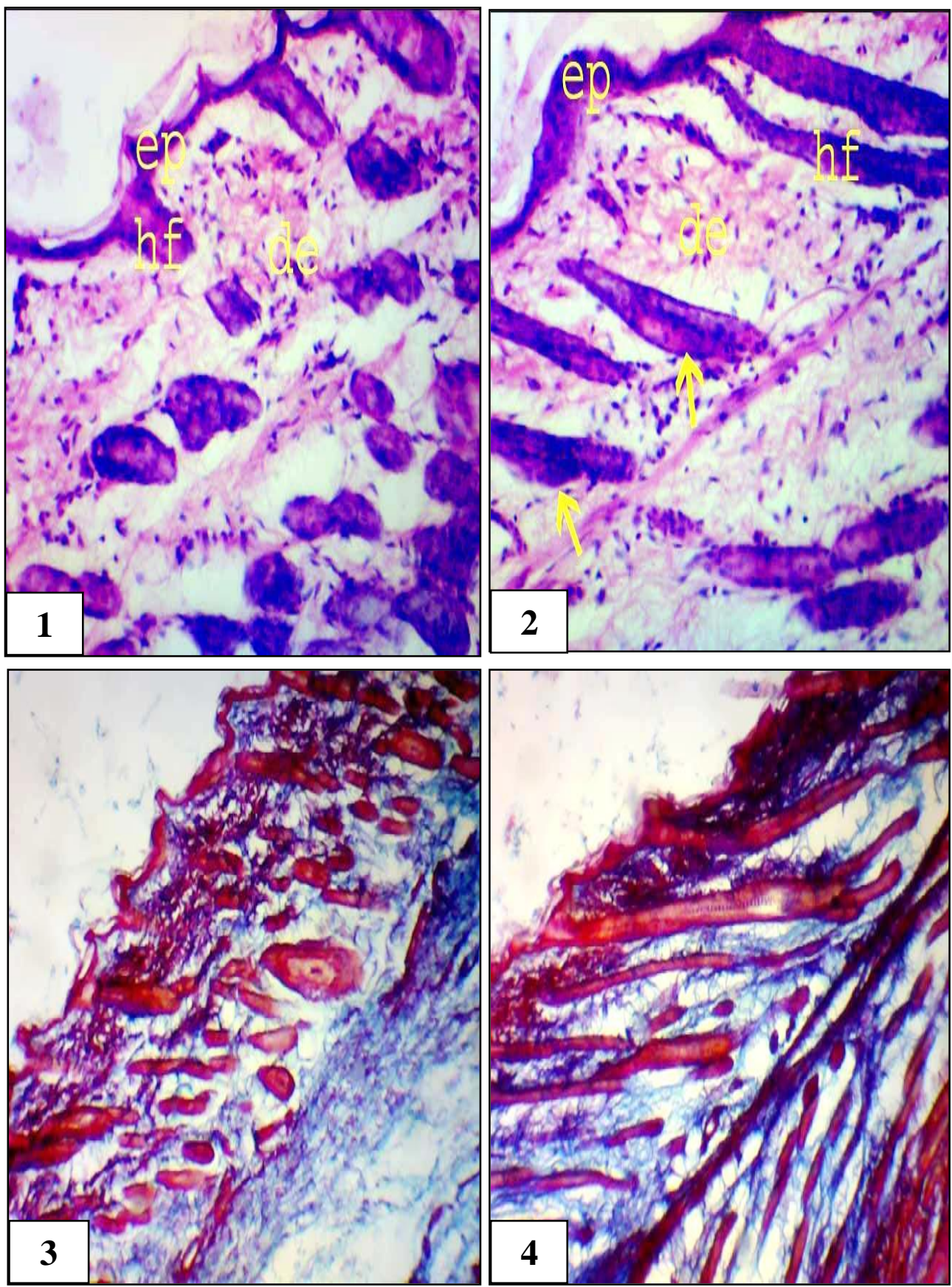

Figs. 1-26: photomicrographs of sections in skin tissue of the control and treated groups

Figs. 1-4: showing the skin tissue of the control group.

Figs. 1, 2:showing well developed epidermal (ep) and dermal layers (de) with hair follicles (hf) and sebaceous glands $(\rightarrow)$. ( H\& E X100)

Figs. 3, 4: control rats showing numerous collagen bundles scattered in the epidermal and dermal layers.

( Mallory'strichrome stain x 100) 

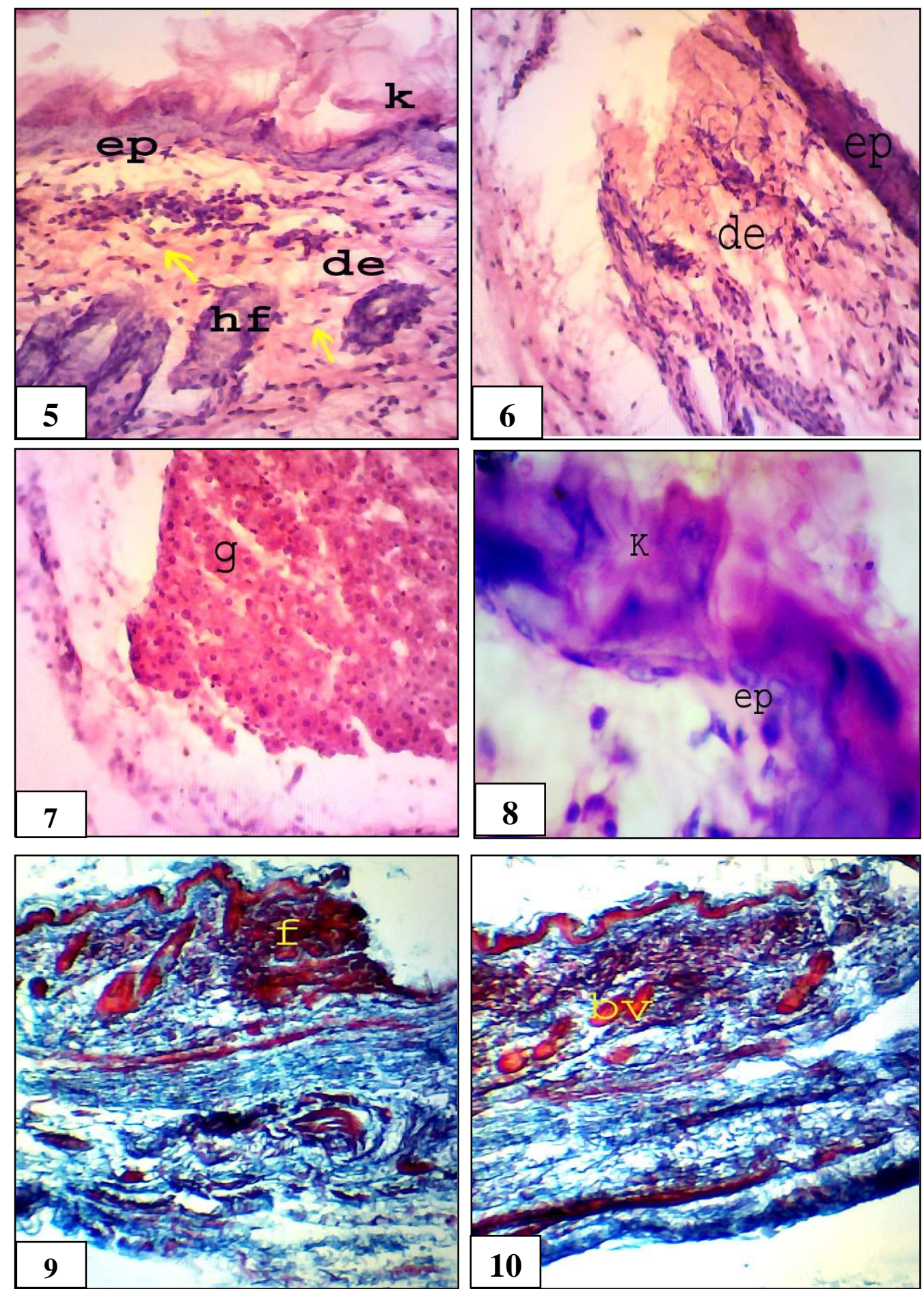

Figs. 5-10:photomicrographs of the skin tissue of rats five days post-carrageenan injection

Figs. 5-8: showing distorted hair follicles (hf) with numerous fibroblasts $(\rightarrow)$, the undetectable cellular structure of the epidermal layer (ep) with highly distorted and thickened keratin layer (k), fibrosis, and absence of hair follicles in the dermal layer (de), presence of debris of degenerated cells and large granulomatous area (g) in the dermal layer.

(5- 7 H\& E X100 ; 8 X400)

Figs. 9,10:showing highly increased collagen fibres in the epidermal and dermal layers. Notice: red brightly stained congested blood vessels (bv) and fibrotic areas (f). (Mallory'strichrome stain X100) 

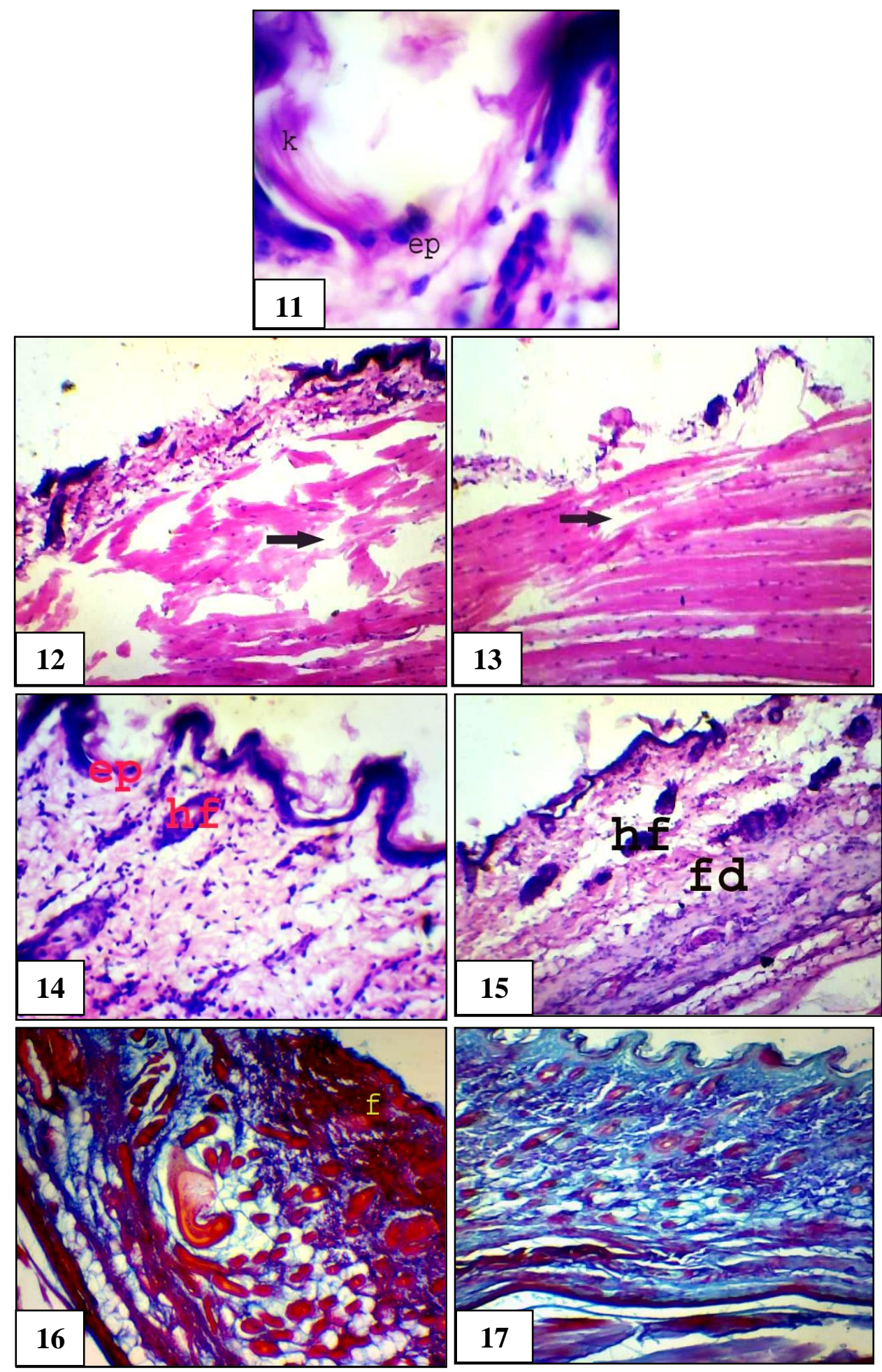

Figs. 11-17:photomicrographs of the skin tissue of rats twenty-one days post- carrageenan injection.

Fig. 11:showing a thickened keratin layer (k)with a highly affected and distorted epidermal layer (ep). ( H\& E X400)

Figs. 12, 13:showing ruptured, discontinuous $(\rightarrow)$ and faintly stained skeletal muscle fibres.( H\& E X100)

Figs. 14, 15: showing an absence of the cellular structure of the corrugated epidermal layer, highly distorted and reduced hair follicles (hf) with signs of fatty degeneration (fd). ( H\& E X100)

Figs. 16, 17:showing highly increased collagen fibres and fibrotic areas (f) in the epidermal and dermal layers. 

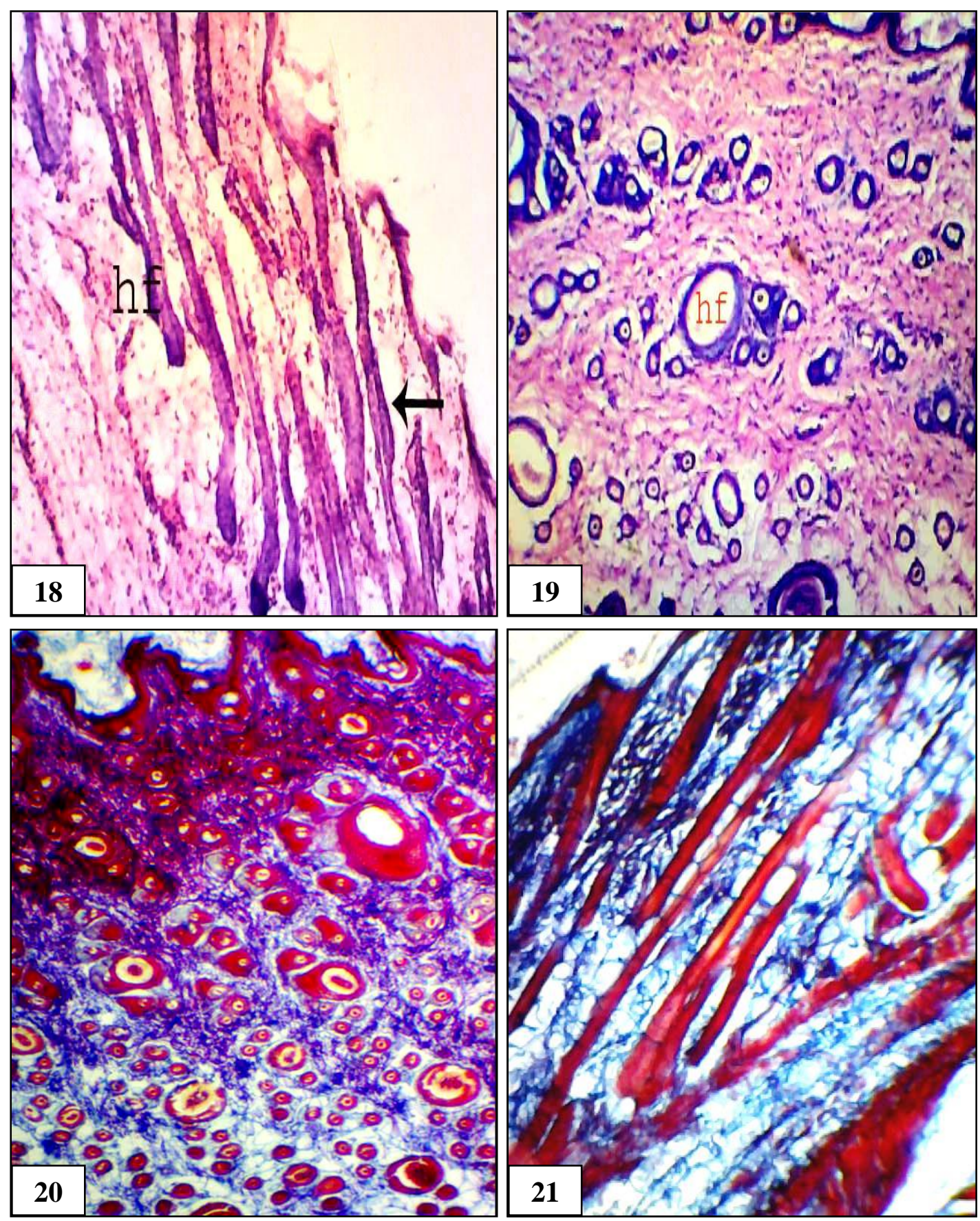

Figs. 18-21:photomicrographs of the skin sections of rats administrated AFA for five and twenty-one days

Figs. 18,19:showing normal appearance of the epidermal and dermal layers with highly increased and well-developed hair follicles (hf) in the expanded dermal layer with their sebaceous glands $(\rightarrow)$. (H \& E X100)

Figs. 20, 21: showing normal distribution of collagen fibres in the epidermal and dermal layers after five (20) and twenty-one days (21). 

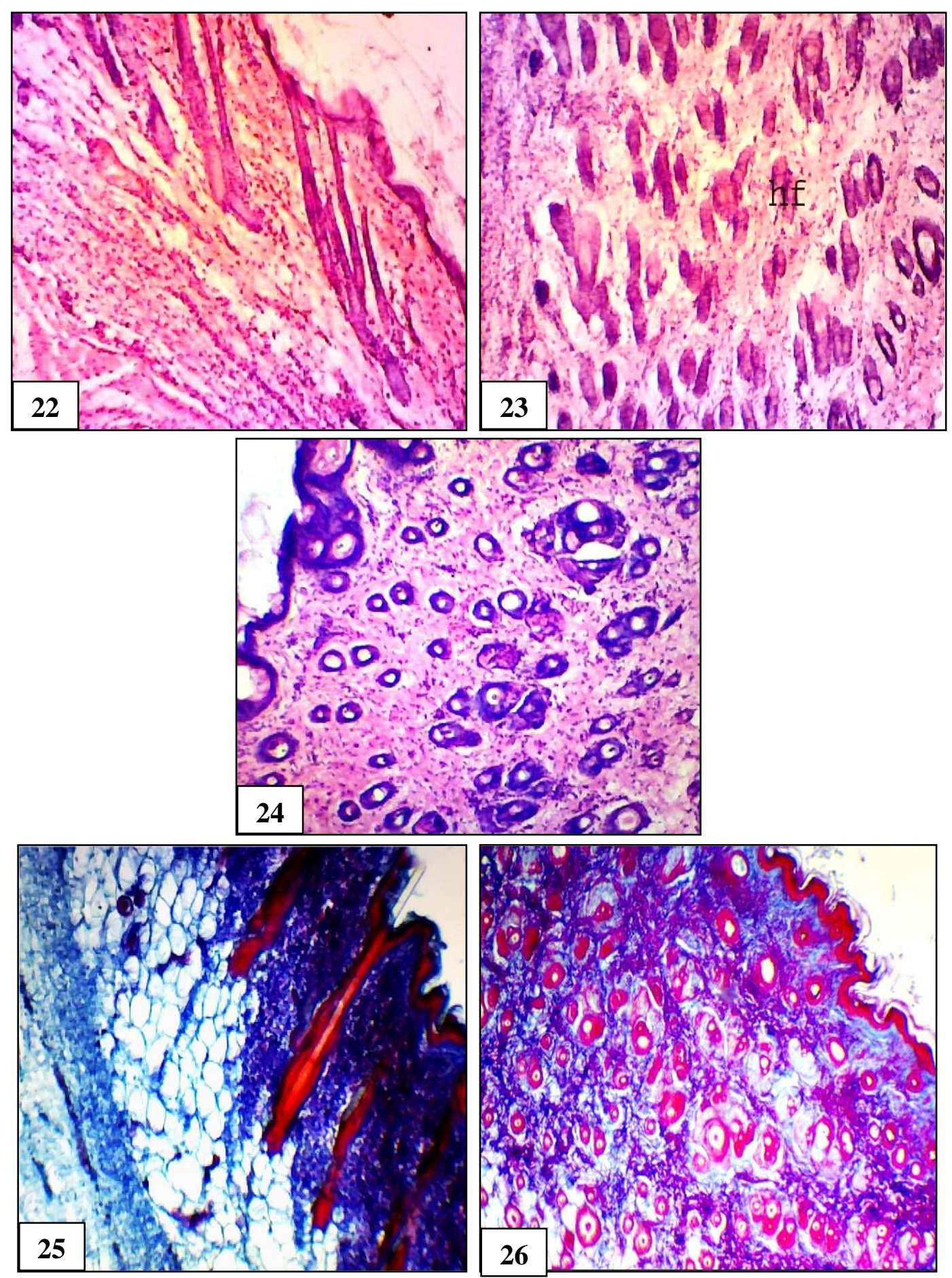

Figs. 22- 26: photomicrographs of the skin sections of rats administrated AFA post-carrageenan injection for five and twenty-one days

Figs. 22, 23, 25: showing a somewhat normal appearance of the epidermal and dermal layers with slightly increased collagen fibres in the dermal layer after five days. (29\& 30 H \& E X100 ;32 Mallory's trichrome stain X100)

Fig. 24: showing a normal structure of the epidermal and dermal layers with highly increased and well-developed hair follicles in the expanded dermal layer after twenty-one days. ( H\& E X100)

Fig. 26: showing somewhat normal distribution of collagen fibres in the epidermal and dermal layers after twenty-one days. (Mallory's trichrome stain X100) 

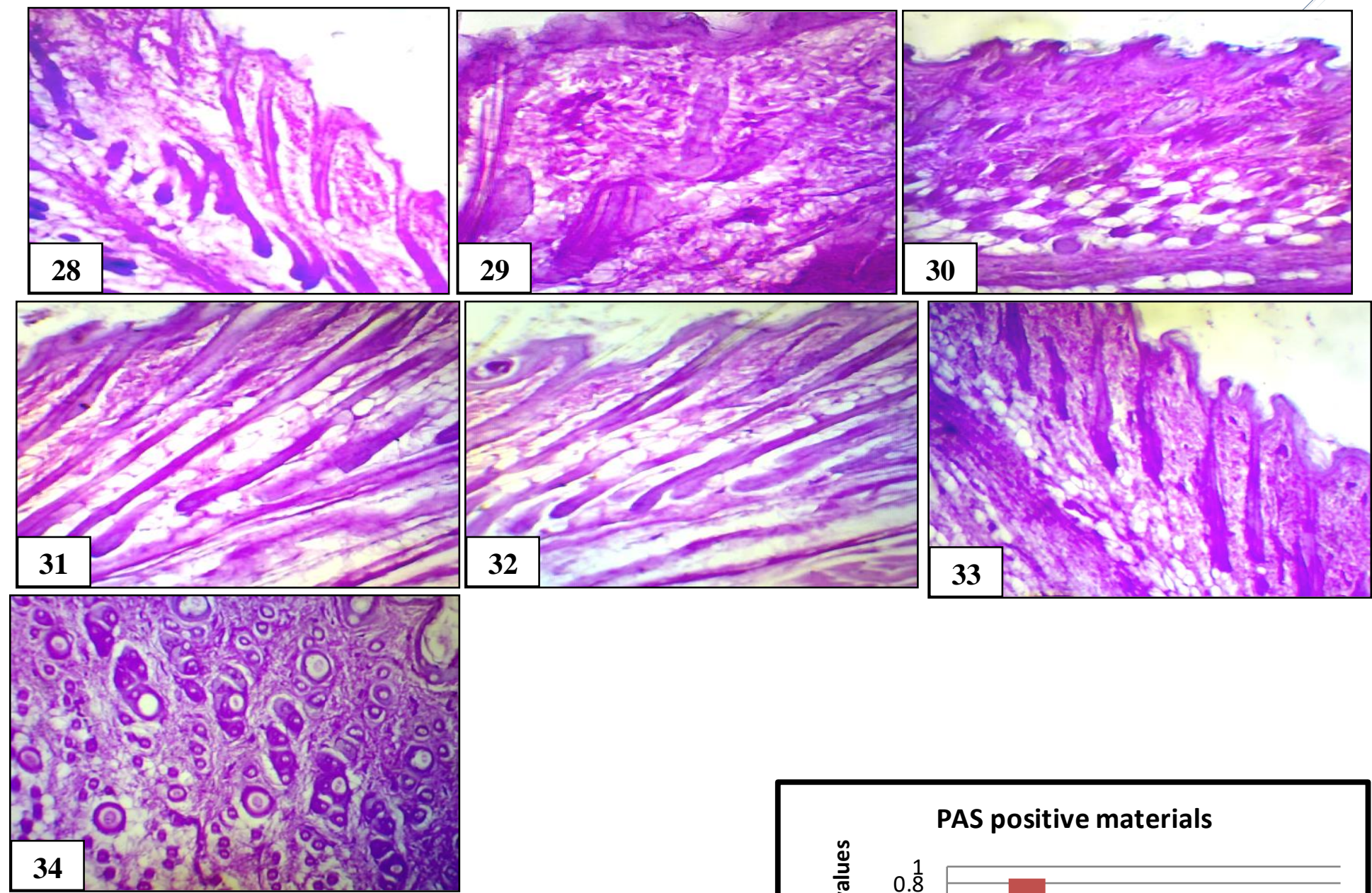

Figs. 28-34: photomicrographs of sections in skin tissue of the control and treated groups. (PAS)

Fig. 28 A: photomicrograph showing normal distribution of polysaccharides in the epidermal and dermal layers of the skin of the control group.

Notice: moderately to deeply stained staining affinity in hair follicles and sub-dermal muscle fibres with less stained connective tissue. (X 100)

Figs. 29, 30: photomicrographs showing increased content of polysaccharides in the corrugated epidermal and destructed dermal layers of the skin sections of carrageenan group after five (Fig. 29) and twenty-one days (Fig. 30). (29 X $200 ; 30$ X 100)

Figs. 31,32:photomicrographs showing normal distribution of polysaccharides in the skin sections of the AFA group after five (Fig. 31) and twenty-one days (Fig. 32). ( X 100) Figs. 33, 34:photomicrographs of sections of the skin tissue of the AFA +Carr group showing slightly increased polysaccharides content after five (Fig. 33) and twenty-one days (Fig. 34). (X 100)

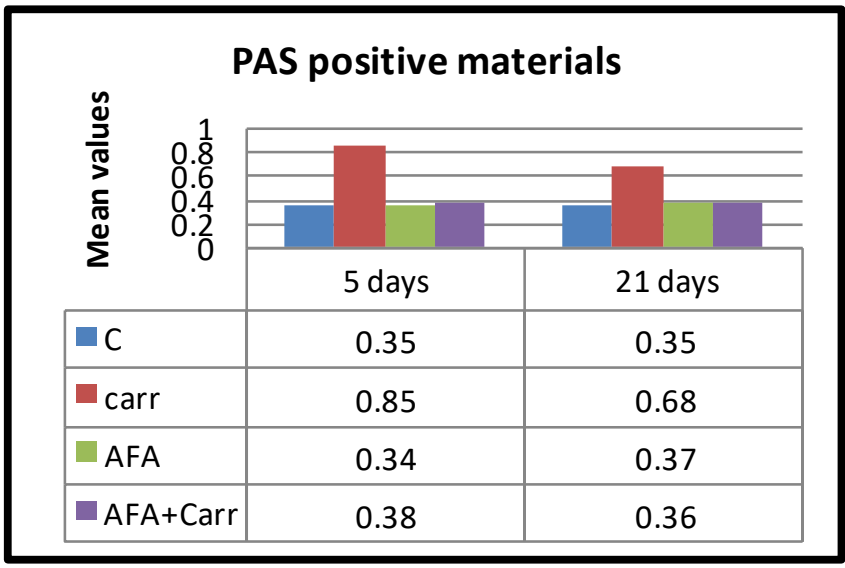

Fig. 35:mean values of PAS-positive materials relative to the control value. 

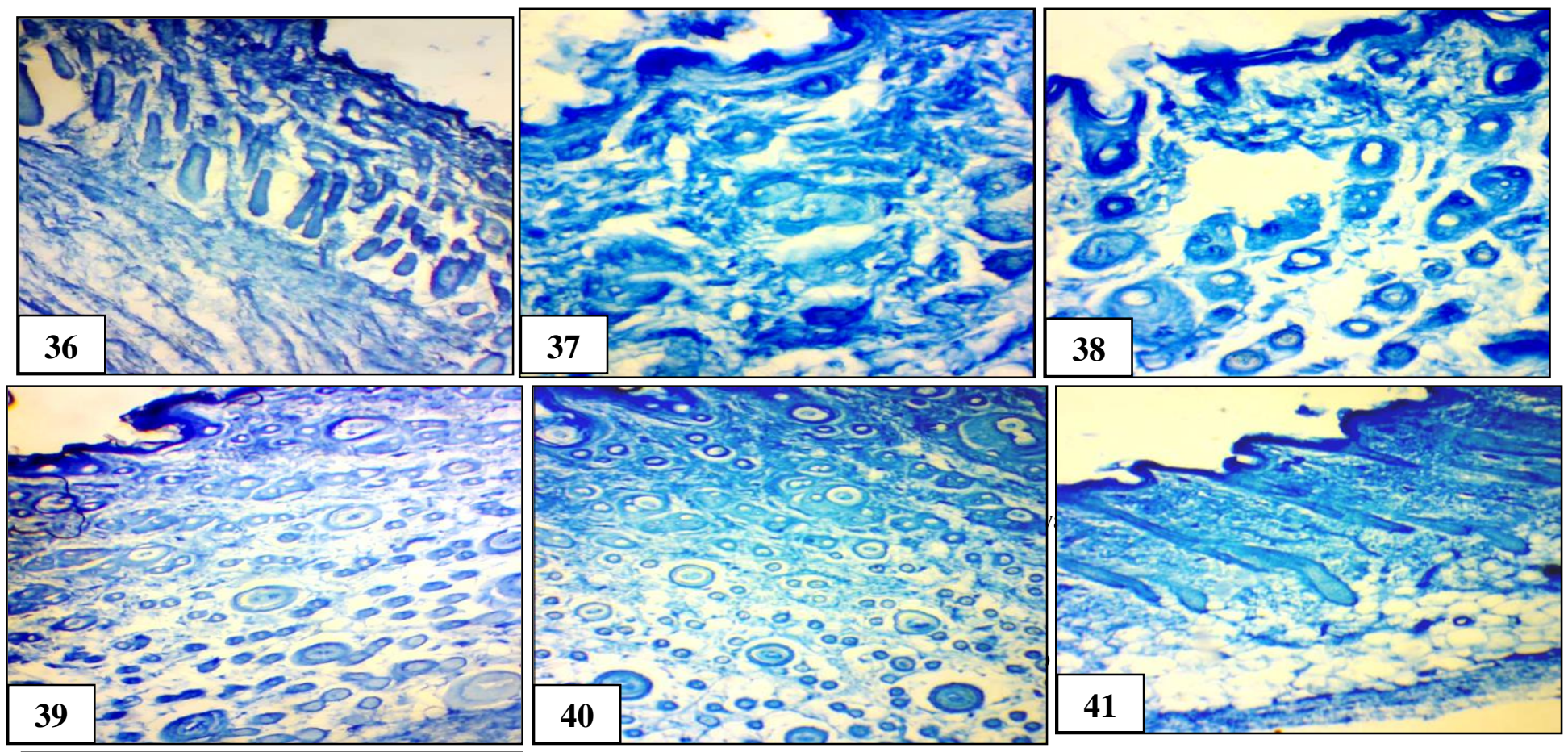

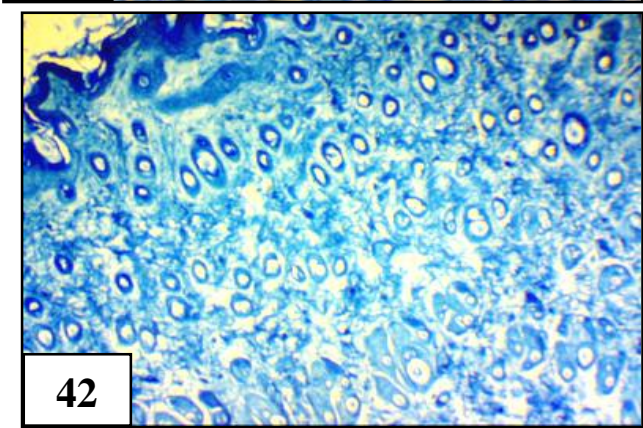

Figs. 36-42: photomicrographs of sections in skin tissue of the control and treated groups. (Mercuric bromophenol blue)

Fig. 36: photomicrograph of a section of the skin of the control group showing normal protein content in the epidermal and dermal layers.Notice: moderately stained epidermal layers, hair follicles, and sub-dermal muscle fibres with less stained connective tissue.

(X 100)

Figs. 37, 38:photomicrographs showing densely stained total protein all over the skin tissue of the carrageenan group after five (Fig. 37) and twenty-one days (Fig. 38). (X 200)

Figs. 39, 40:photomicrographs of sections of the skin of the AFA group showing normal distribution of protein content all over the skin tissue after five (Fig. 39 and twenty-one days (Fig. 40).

(X 100)

Figs. 41, 42:photomicrographs showing slightly increased total protein content in the epidermal and dermal layers in the skin tissue of AFA+ Carr group as compared

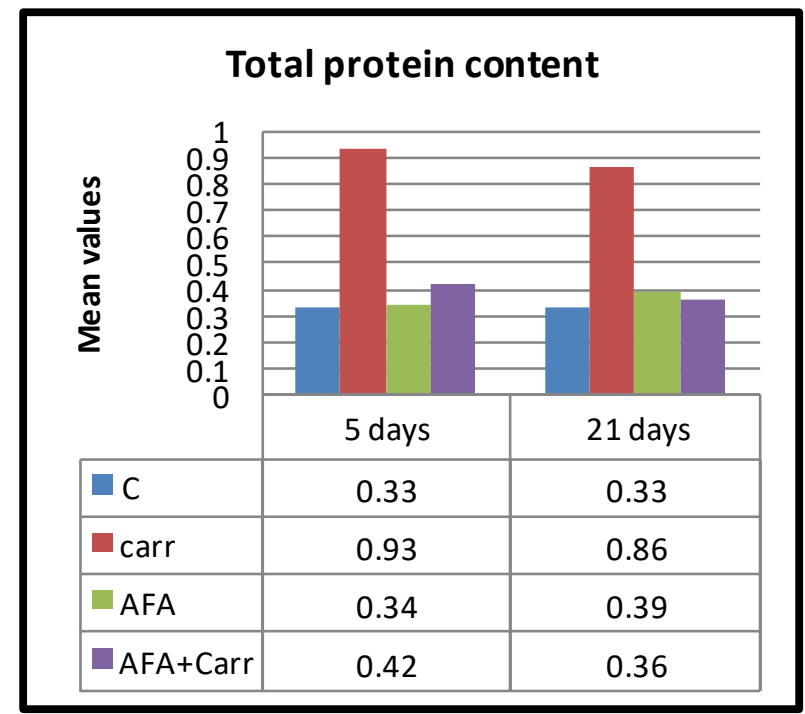

Fig. 43: mean values of total protein content relative to the control value. 


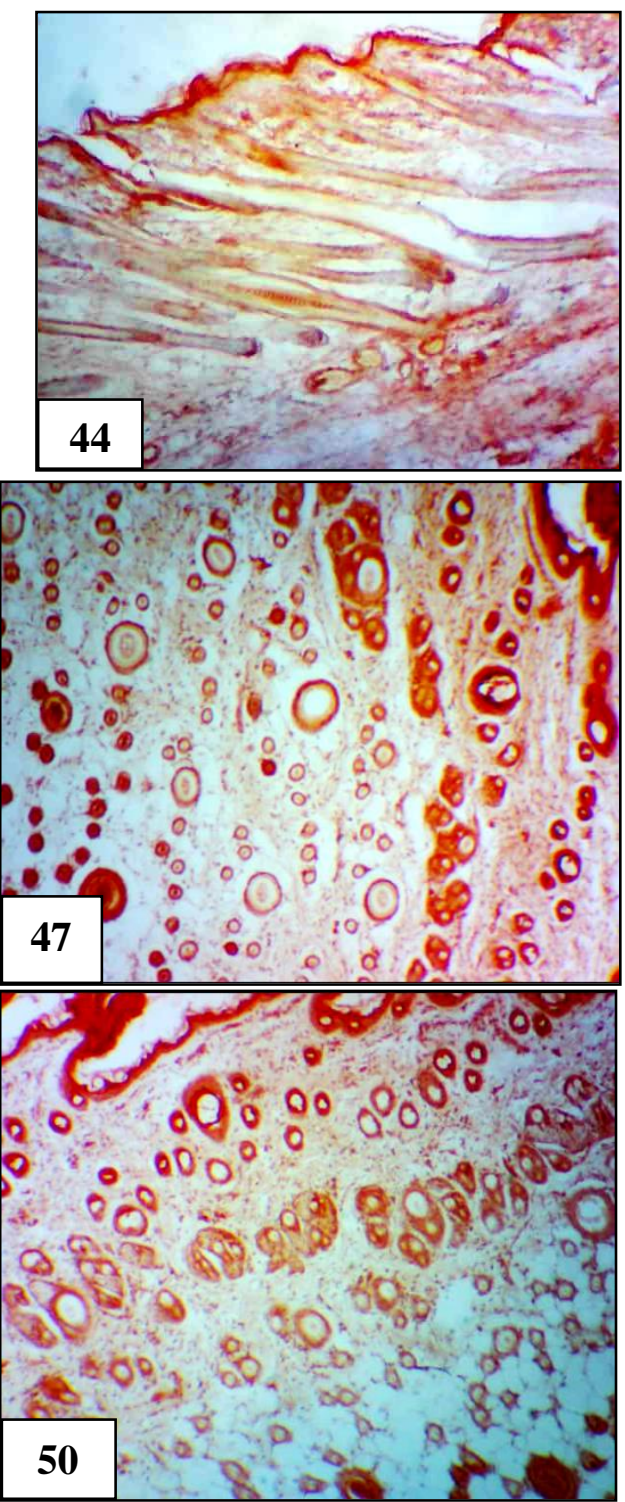

Figs. 44-50: photomicrographs of sections in skin tissue of the control and treated groups. (Congo red $X$ 100)

Fig. 44: photomicrograph of a section of the skin of the control group showing faintly stained amyloid protein in the dermal and epidermal layers.

Figs. 45, 46:photomicrographs showing increased amyloid protein in the corrugated epidermal and destructed dermal layers of the skin tissue of carrageenan treated group after five (Fig. 45) and twenty-one days (Fig. 46).

Figs. 47,48:photomicrographs of sections of the skin tissue of group AFA showing somewhat normal distribution of amyloid protein in the epidermal and dermal layers after five (Fig. 47) and twenty-one days (Fig. 48). Figs. 49, 50:photomicrographs showing slightly increased amyloid protein content in the epidermal and dermal layers in the skin tissue of AFA+ Carr group after five days (Fig. 49) and normal distribution after twenty-one days (Fig. 50) as compared to the control group.

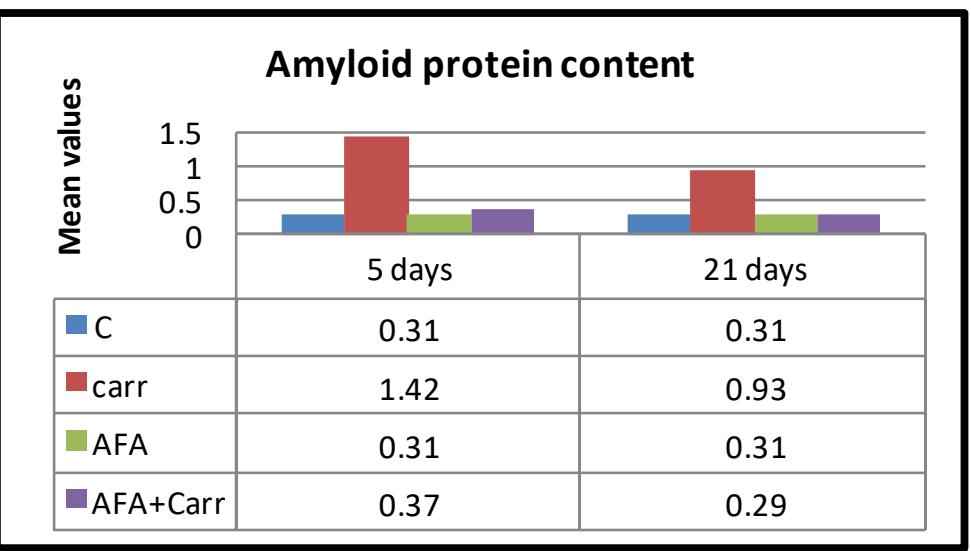

Fig.(51): Mean values of amyloid protein content relative to the control value. 

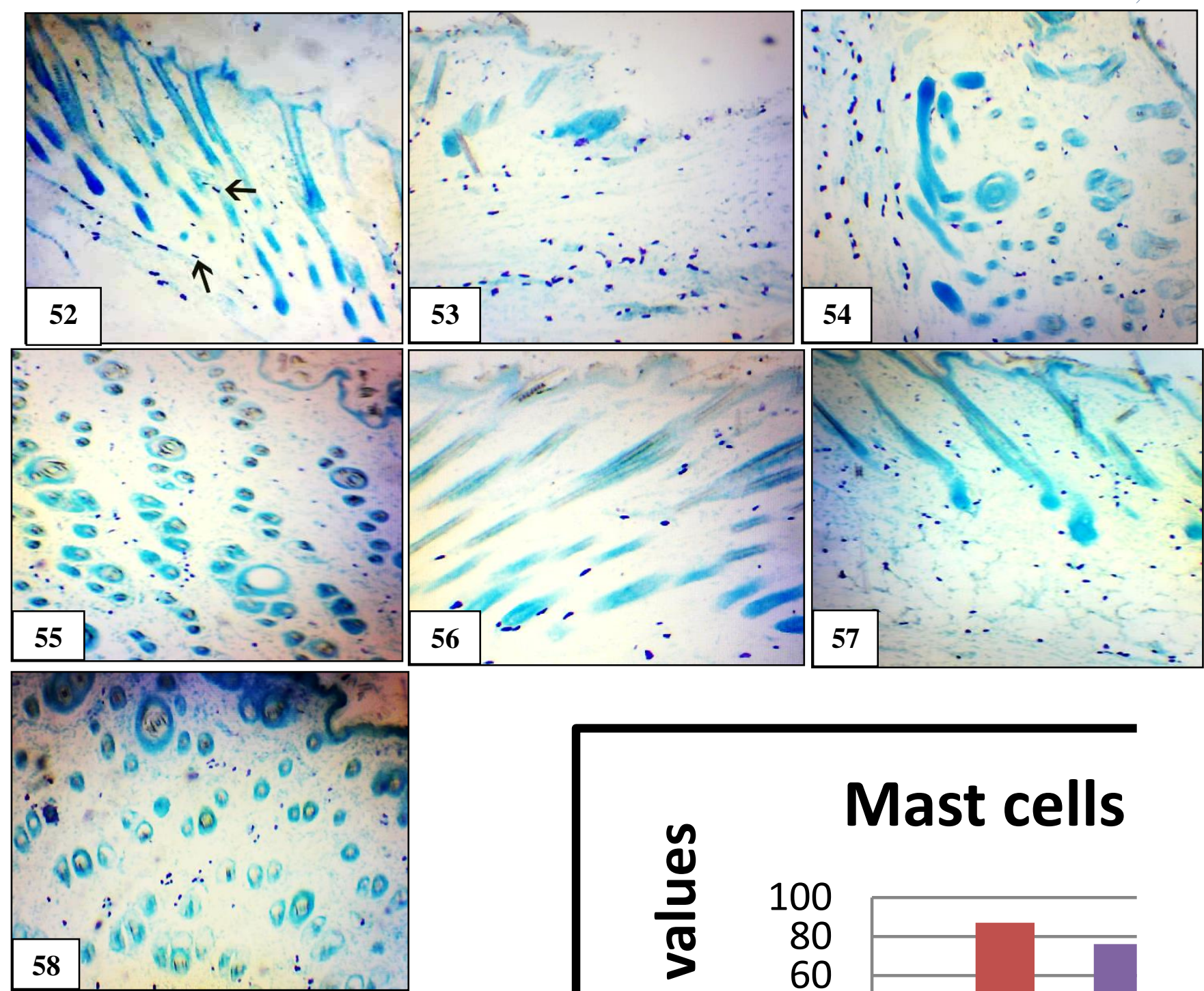

Figs. 57-58: photomicrographs of sections in skin tissue of the control and treated groups. (Toluidine blue $\mathrm{X}$ 100)

Fig. 52: photomicrograph of a section of the skin of the control group showing normal distribution of mast cells $(\rightarrow)$.

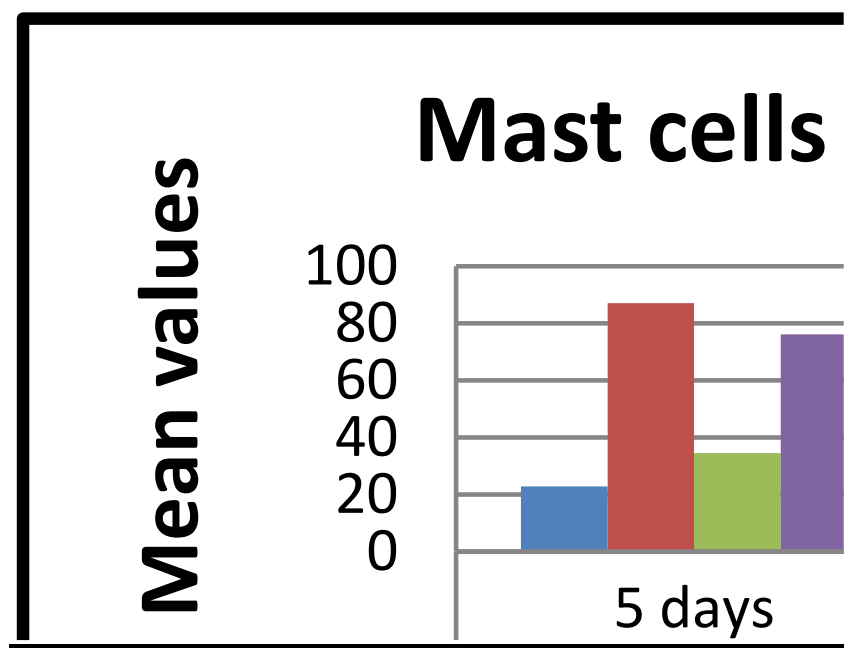

Figs. 53,54:photomicrographs showing increased mast cells of carrageenan group after five (Fig. 53) and twenty on days (Fig. 54).

Fig. 59: mean values of mast cells relative to the control

Figs. 55,56:photomicrographs of sections of the skin of the value. AFA group showing slightly increased mast cells after five (Fig. 55) and twenty-one days (Fig. 56).

Figs.57,58:photomicrographs showing increased mast cells in the skin of the AFA + Carr group after five (Fig. 57) and twenty-one days (Fig. 58) post-treatment. 


\section{Discussion}

Concerning the histopathological changes, in the present study, the skin tissue of rats treated with carrageenan for five and 21 days post-treatment resulted in several histopathological lesions including thickened keratin, distortion, fibrosis, cellular debris, loss of hair follicles, granuloma, loss of cellular structures. The present results come in agreement with the work of Abdel-Raouf (2006) who reported that the skin of rats treated with carrageenan showed many degenerative changes included disturbed keratin layer and hair follicles, irregular epidermis, vacuolation in the dermis, increased fibroblasts, affected muscle fibers and small areas of hemorrhage. The chronic granuloma observed postcarrageenan injection was noticed by Massimo (1972) who stated that granuloma occurred mainly due to the marked cellular emigration which happened during the acute response.

Ezeamuzie and Njoku (1992), Houle et al. (2005), and Ma et al. (2013) reported that the histopathological results of edema paws showed that carrageenan-induced swelling and neutrophil accumulation at the site of inflammation. The accumulation of leukocytes at the inflammatory site results from the interaction between endothelial cells and leukocytes (Granger and Kubes, 1994).

The present results are supported by a workshop conducted by Kumar et al. (2014) who reported that the myofibrils were separated from the epidermis by a wide gap in the muscle tissue the second day after the injection of carrageenan. Similarly, the muscle tissue at the site of injection exhibited leucocytic infiltration followed by necrotic myositis indicating the property of carrageenan as an indicator of inflammation.

In the present study, skin sections examined five and twenty-one days following AFA administration showed nearly normal appearance of the epidermal and dermal layers, highly increased and well-developed hair follicles with their sebaceous glands. Also, the epidermal and dermal layers of rats administrated AFA postcarrageenan injection were resuming their normal structure with highly increased and well-developed hair follicles in the expanded dermal layer (after twenty-one days).

Wound healing is a fundamental response to tissue injury that involves a complex set of cellular, physiological and molecular events targeted toward the restoration of the structural and functional integrity of the damaged tissue (Priya et al., 2004). Results of the current work are supported by the work done by Hagino and Masanobu (2003) who revealed that uses of algal proteins or their derivatives are important in conferring moisture retention on hair and skin. On the other hand, algal proteins show a strong affinity with hair or skin to improve their nourishments. Moreover, rich protein

contents and biologically dynamic growth factors in many of the algae can facilitate the preparation of cosmeceuticals. Furthermore, cosmeceuticals are supposed to be involved in healing and repairing damaged skin with moisturizing and maintaining the nourishment as well.

Bhat and Madyastha (2000) revealed that mycosporine-like amino acids (MAAs), AFAphycocyanins, and AFA- phytochrome which, to different extents, are endowed with anti-inflammatory properties and powerful antioxidants. They also added that $5 \%$ to $10 \%$ of the dry weight of the algae is represented by phycocyanins molecules which have powerful antiinflammatory effects, similar to those of non-steroidal anti-inflammatory drugs, but of course without any side effects. In particular, it has been proven that phycocyanins are selective COX-2 inhibitors, as powerful as the drugs rofecoxib and celecoxib. Phycocyanins also inhibits the formation of leukotriene $\mathrm{B}_{4}$ (an inflammatory metabolite of arachidonic acid).

The present results also are in agreement with those of Patel et al. (2005) and Abd El-Baky et al. (2009) who detected that proliferation and growth stimulation activities of blue-green algae seem to be directly associated with either C-PC or potentially other unidentified compounds. They also added that blue-green algae contain a mixture of proteins and carotenoids which interact synergistically in mediating proliferation of skin cells and hence contribute significantly to wound healing and tissue regeneration. Also, Abed et al. (2009) and Plaza et al. (2009) reported that the anti-inflammatory and antioxidants effects of blue-green algae and C-PC satisfied the basic criteria for being used in wound management.

Kushak et al. (2000) reported that AFA decreased the plasma level of arachidonic acid, thus reinforcing its general anti-inflammatory activity. AFA is also rich in specific nutraceutical molecules, such as phenylethylamine (PEA) and unique AFA-phycocyanins, with strong antioxidant and anti-inflammatory properties on one hand and powerful neuromodulating and neuroprotective activities on the other hand (Scoglio et al., 2009).

Gur et al. (2013) showed that firstly, phycocyanin found in blue-green algae directly enhances wound repair by its anti-oxidant property and scavenging destructive free radicals mechanism. Secondly, the stimulation of keratinocytes is one mechanism by which phycocyanin might enhance wound repair. They also added that the minerals, phycobiliproteins, vitamins, beta carotene, fatty acids, polysaccharides, phenolic compounds, and volatile compounds present in the microalgae may accelerate wound healing by acting as an anti-oxidant and 
scavenging destructive free radicals responsible for cell death.

Ismail et al. (2013) showed that blue-green algae increase the stem cell trafficking or homing in animals through induction of a transient boosting in the population of stem cells in animal's circulatory systems. Two of these natural products are Stem Flo and Stem Enhance, which are extracted from the AFA plant (Jensen et al., 2007). Mansilla et al. (2006) supported that the mobilization, migration, and differentiation of bone marrow stem cells in the target tissue constitute a natural phenomenon of healing in the human body. Aphanizomenon flos- aquae stimulates the release of Adult MSC which can facilitate quick healing of injured/fractured bone ( Ochube et al.,2017).

The present results extend and support the work of Vestola et al. (2014) who revealed that BGA is high in various $\mathrm{B}$ vitamins (including $\mathrm{B}_{12}$ ), carotenoids, and minerals including calcium, iron, magnesium, selenium, manganese, potassium, and zinc. It is also a great source of gamma-linolenic acid (GLA), an essential fatty acid that stimulates skin and hair growth. They also added that many of these vitamins and minerals have strong antioxidant properties which help to eliminate toxins and fight against diseases. Yogianti et al. (2014) recorded the inhibitory effects of dietary blue-green algae on UVBinduced skin inflammatory responses and carcinogenesis, which were attributed to the algae's anti-inflammatory and antioxidant effects.

Maxim et al. (2015) showed that after the bluegreen algae powder had been orally administered for eight weeks, a highly significant increase in the carotenoid concentration of skin was observed. They also added that oral administration of the powdered algae improved the antioxidant status of the skin as demonstrated by the highly significant increase of the carotenoid concentration. So, the obtained increase can be directly correlated with the increased ability of the skin to counteract generated free radicals.

As regards the collagen fibres in the present study highly increased collagen fibres and fibrotic areas were detected in the epidermal and dermal layers after 5 and 21 days post-carrageenan injection.

According to Robertson and Schwertz (1953)carrageenan injected subcutaneously in the guinea pigs was able to induce the development of a glaucomatous tissue containing large amounts of collagen. The glaucomatous tissue formation was maximal at about 1 week and was completely desorbed at 46 weeks (Jackson, 1957). In the current study treatment of rats with AFA post-carrageenan injection showed increased collagen fibres in the dermal layer after five days, while a somewhat normal distribution of collagen fibres was detected after twenty-one days. Maxim et al. (2015)showed that the systemically administered bluegreen algae (Spirulina platensis) slightly but insignificantly improved the dermal collagen concentration. They expected that additional antioxidant protection of skin will result in a decrease in the number of free radicals interacting with the dermal elastic fibers, such as collagen and elastin.

In the present investigation, the carrageenan group exhibited a significant increase in PAS-positive materials in the corrugated epidermal layer and destructed dermal layer all over the experimental periods.

In the current study, AFA treated group and the AFA + Carr group exhibited a non-significant increase in PASpositive materials all over the experimental periods.

Seaweeds are found to be a source of novel nutraceuticals sulfated polysaccharides and peptides(Jimenez-Escrig et al.,2011). Carbohydrates such as starch, sugars, glucose, and other polysaccharide exist in microalgae(Brown et al., 1997). There is no restriction for the use of dried total microalgae in foods or feeds, due to their high overall digestibility. Besides the biological functions of some microalgal species have been related to their polysaccharides. Complexes of polysaccharide from microalgae such as glucose and a variety of combinations of mannose, galactose, rhamnose, $\mathrm{N}$-acetyl glucosamine, $\mathrm{N}$ acetylgalactosamine, and arabinose; these complexes have immune-stimulatory effects (Pugh and Pasco, 2001)

Concerning the histochemical changes of total protein, the present results showed that the carrageenan group exhibited a significant increase in the total protein of skin tissue as compared to the control group all over the experimental periods.

Results of the present study come in agreement with the work done by Jean et al. (2008) who noticed that carrageenan up-regulate pro-inflammatory proteins (inducible nitric oxide synthase (iNOS) and cyclooxygenase $2(\mathrm{COX}-2)$ ) at the site of inflammation.

Results of the present study also come in agreement with those of Vazquez et al. (2015) who realized that there were diverse systemic changes including increased levels of acute-phase proteins, such as C-reactive protein(CRP) and fibrinogen after carrageenan injection.

In the present study, rats administrated AFA alone showed a non-significant increase of total proteins in skin tissue after five and twenty-one days as compared to the control value. While rats administrated AFA post-carrageenan injection exhibited a significant increase in protein content after five days and a non-significant increase after twentyone days as compared to the control value

The present results are supported by Becker (2007) who revealed that microalgae have the potential to become an alternative protein source because several strains contain proteins of high quantities (more than $50 \%$ of dry weight) and qualities. The presence of essential amino acids, such as lysine, leucine, isoleucine, and valine (comprising 35\% of essential amino acids in muscle proteins of humans), contributes to the high quality of microalgal proteins, making them highly suitable for use as direct supplements (both for animal and human consumption) or as nutraceuticals(Dewapriya and Kim, 2014).

Spolaore et al. (2006) reported that an extract rich of 
protein from BGA (Spirulina) can repair the signs of skin aging and can stimulate collagen synthesis. Kim and Wijesekara (2010) revealed that algae bearing a rich source of secondary metabolites, including functional nutrients and associated bioactive peptides, then other marine organisms. Indeed, algae bioactive peptides could be a natural source with prominent biological activities besides its health effects.

Concerning the histochemical changes of Amyloid$\beta$ protein the current study recorded a significant increase in amyloid $\beta$ protein content in skin tissue of carrageenan group relative to the control group all over the experimental periods.

Amyloids are insoluble fibrous protein aggregates sharing specific structural traits. They are insoluble and arise from at least 18 inappropriately folded versions of proteins and polypeptides present naturally in the body(Alvarado et al., 2000). These misfolded structures alter their proper configuration such that they erroneously interact with one another or other cell components forming insoluble fibrils. They have been associated with the pathology of more than 20 serious human diseases in that abnormal accumulation of amyloid fibrils in organs may lead to amyloidosis and may play a role in various neurodegenerative disorders (Pulawski et al., 2012).

Kadowaki et al. (2005) showed that amyloid deposition is associated with mitochondrial dysfunction and the resulting generation of reactive oxygen species (ROS), which can initiate a signaling pathway leading to apoptosis.

The present study showed that rats administrated AFA alone and AFA post-carrageenan injection exhibited nonsignificant changes in amyloid $\beta$ protein content relative to the control group after five and twenty-one days posttreatment.

Studies have reported various health benefits of BGA, including immune functions, anti-inflammatory, antibacterial, anti-viral, anti-cancer, anti-diabetic, hypocholesterolemic, and hypotriglyceridemic properties ( Jensen et al., 2008; El-Depsi, 2016). The present study is supported by the work of Yang et al. (2011) who revealed that long-term BGA supplementation in mice did not induce any evident adverse side-effects.

Concerning the histochemical changes of mast cell count, the present study showed a significant increase in mast cell count in skin tissue of carrageenan treated group after five and twenty-one days post-treatment.

Vinegar et al. (1987) observed that dermal mast cells increased in injured skin by carrageenan injection.

The present investigation comes in agreement with the result of Radhakrishnan et al. (2003) who reported that inflammatory changes were observed histologically for both the joint and muscle tissues after injection of carrageenan. Acute inflammation was observed for the first $24 \mathrm{~h}$ with edema and neutrophilic infiltration evident as early as $4 \mathrm{~h}$. At 1 week, the inflammation converted to primarily macrophage response with scattered mast cells.
Mast cells are an important source of cytokines during inflammatory responses. In various settings, they can release a wide array of cytokines (Kalesnikoff and Galli, 2008). Mast cells also facilitate the interaction of the central circulatory system with a local inflammatory site, in part by promoting the recruitment of cells into a site of inflammation, primarily from the bloodstream. For example, mast cells can mediate early neutrophil recruitment, which is often the first line of defense against pathogens (St-John et al., 2011). Because of their preponderance at the host-environment interface and their large repertoire of cell surface receptors, such as the highaffinity $\operatorname{IgE}$ receptors and complement component receptors, mast cells are capable of responding to a wide variety of exogenous and endogenous stimuli, making them versatile detectors of allergens, tissue injury and infection (Abraham and St John, 2010).

In the present study, AFA treated group exhibited a non-significant increase of mast cells in the dermal layer all over the experimental periods, while rats administrated AFA post-carrageenan injection exhibited a significant increase of mast cells after five days with a non-significant increase after twenty-one days.

Romy et al. (2003) reported that phycocyanin reduced edema, histamine (Hi) release, myeloperoxidase (MPO) activity, the levels of prostaglandin (PGE2), and leukotriene (LTB4) in the inflamed tissues. These antiinflammatory effects of phycocyanin can be due to its scavenging properties toward oxygen reactive species (ROS), its inhibitory effects on COX-2 activity, and Hi release from mast cells.

\section{References:}

Abd-El Baky, H.H.; El-Baz, F.K., and El-Baroty, G.S. (2009): Enhancement of antioxidant production in Spirulina platensis under oxidative stress. Acta. Physiol. Plant, 31:623-631.

Abdel-Raouf, O.M. (2006): Impact of an antiinflammatory drug combined with heat stress on certain haematological, biochemical and histological parametars. Ph. D. Thesis, Zoology Department, Faculty of Science, Al-Azhar University.

Abed, R. M. M.; Dobretsov, S. and Sudesh, K. (2009): Applications of cyanobacteria in biotechnology. J. Appl. Microbiol., 106:112.

Abraham, S.N., and St John, A.L. (2010): Mast cellorchestrated immunity to pathogens. Nat. Rev. Immunol., 10(6): 440-452.

Alvarado, M.R.; Merkel, J.S. and Regan, L. (2000): A systematic exploration of the influence of the protein stability on amyloid fibril formation in vitro. P.N.A.S., 97 (16): 8979-8984.

Bancroft, J.D., and Gamble, M. (2002): Theory and Practice of Histological Techniques. $5^{\text {th }}$ ed., Churchill Living Stone. London, pp: 150-152. 
Becker, E. (2007): Micro-algae as a source of protein. Biotechnol. Advances, 25(2): 207-210.

Benedetti, S.; Benvenuti, F.; Scoglio, S. and Canestrari, F. (2010): Oxygen radical absorbance capacity of phycocyanin and phycocyanobilin from the food supplement Aphanizomenon flos- aquae. J. Med. Food, 13(1):223-227.

Bhat,V.B. and Madyastha,K.M.(2000): C-phycocyanin, a potent peroxyl radical scavenger in vivo and in vitro. Biochem. Biophys. Res. Commun., 275:20-25.

Brown, M.R.; Jeffrey,S.W.; Volkman,J.K. and Dunstan,G.A. (1997): Nutritional properties of microalgae for mariculture. Aquaculture, 151: 315-331.

Chakdar, H.; Jadhav,S.D.; Dhal, D.W. and Pabbi,S. (2012): Potential applications of blue green algae. J. of Sci. and Indust. Res. , 71: 12-30.

Cotran, R.S.; Kumar,V. and Robbins,S.L. (2004): Pathologic Basis of Disease, $7^{\text {th }}$ ed., Robbins and Cotran, Philadelphia. pp:47-118.

Dash,S. and Kanungo,S.K. (2013): Antiinflammatory activity of Aponogeton natans (Linn.) Engl. and Krause in different experimental animal models. Scholars Res. Libr., 5 (1):136-140.

Dewapriya,P. and Kim,S.K. (2014): Marine microorganisms: an emerging avenue in modern nutraceuticals and functional foods. Food Res. Int., 56: 115-125.

Drury,R. and Wallington,E. (1980): Carleton's Histological Technique. $4^{\text {th }}$ ed., Oxford. Univ. Press, New York.

El- Depsi,S.M. (2016): Evolution of the role of glibenclamid and Aphanizomenon flosaquae extract on some organs of the induced diabetes rats. M.Sc. Thesis, Zoolgy Department,Faculty of Science, Al-Azhar University.

El- Depsi,S.M. (2016): Evolution of the role of glibenclamid and Aphanizomenon flosaquae extract on some organs of the induced diabetes rats. M.Sc. Thesis, Zoolgy Department,Faculty of Science, Al-Azhar University.

Ezeamuzie,I.C. and Njoku,A.C. (1992): The role of neutrophils in acute and chronic inflammation in rats. Afr. J. Med. Sci., 21: 23-28.

Ghosh,A.K.; Hiraswa,N.; Niki,H. and ohuchi,K. (2000): Cyclo-oxygenase to mediated angiogenesis in carrageenan induced granulation tissue in rats. J. Pharmacol. Exp.Therap., 295(2): 802-809 .

Granger,D.N. and Kubes,P. (1994): The microcirculation and inflammation: modulation of leukocyte-endothelial cell adhesion. J. Leukoc. Biol., 55: 662-675.

Gur,C.S.; Erdogan,D.K.; Onbasılar,I.; Atilla,P.; Cakar,N. and Gurhan,I.D. (2013): In vitro and in vivo investigations of the wound healing effect of crude Spirulina extract and C-phycocyanin. J. Medic. Plants Res., 7(8):425-433.

Haag,S.F.; Taskoparan,B.; Darvin,M.E.; Groth,N.; Lade- mann,J. ; Sterry,W. and Meinke,M.C. (2013): Determination of the antioxidative capacity of the skin in vivo using resonance raman and electron paramagnetic resonance spectroscopy. Exp. Dermatol., 20: 483-487.

Hagino,H. and Masanobu,S. (2003): Use of algal proteins in cosmetics. European Patent, 1: 433-463.

Houle,S. ； Papez,M.D. ； Ferazzini,M. ; Hollenberg,M.D. and Vergnolle,N. (2005): Neutrophils and the kallikreinkinin system in proteinase activated receptor 4-mediated inflammation in rodents. Br. J. Pharmacol., 146: 670-678.

Ismail,Z.M.K.;Kamel,A.M.F.;Yacoub,M.F.Y. and Aboulkhair, A.G. (2013): The effect of in vivo mobilization of bone marrow stem cells on the pancreas of diabetic albino rats (A Histological \& Immunohistochemical Study). Int. J. Stem Cells., 6(1):1-9.

Jackson, D.S.(1957): Connective tissue growth stimulated by carrageenin: the formation and removal of collagen. Biochem. J., 65:277-284.

Jean, Y.; Wu-Fu Chen,W. ; Duh,C. ; Huang,S.; ChiHsin Hsu, C. ; Lin,C.; Sung,C.;Chen, M. and Wen,Z.(2008): Inducible nitric oxide synthase and cyclooxygenase-2 participate in anti-inflammatory and analgesic effects of the natural marine compound lemnalol from Formosan soft coral. European J. Pharmacol., 578: 323-331.

Jensen,G.S.; Ginsberg,D.I. and Drapeau,C. (2001): Blue green algae as an immunoenhancer and biomodulator. J. Amer. Nutraceut. Assoc., 3: 24-30.

Jensen,G.S.; Hart,A.N.; Zaske,L.A.; Drapeau,C.; Gupta,N. and Schaeffer, D.J. (2007): Mobilization of human CD34+ CD133+ and CD34+CD133-stem cells in vivo by consumption of an extract from Aphanizo-menon flos-aquae related to modulation of CXCR4 expression by an L-selectin ligand. Cardiovasc. Revasc. Med., 8(3):189-202. 
Jensen,G.S.;Patterson,K.M. and Yoon,I.(2008): Yeast culture has anti-inflammatory effects and specifically activates NK cells. Comp. Nat. Rev. Immunol., 5(8):606-616.

Jimenez-Escrig, A.; Gómez-Ordóñez,E. and Rupérez, P. (2011): Seaweed as a source of novel nutraceuticals: sulfated polysaccharides and peptides. Adv. Food Nutr. Res., 64: 325-337.

Jugdutt,B.I. (2007): Cyclooxygenase inhibition and adverse remodeling during healing after myocardial infarc-tion. Circulation, 115:288-291.

Kadowaki, H.; Nishitoh,H.; Urano,F.; Sadamitsu,C. and Matsuzawa,A. (2005): Amyloid beta induces neuronal cell death through ROS-mediated ASK1 activation. Cell Death Differ., 12 (1): 19-24.

Kalesnikoff, J. and Galli, S.J. (2008): New developments in mast cell biology. Nat. Immunol., 9(11):1215-1223.

Kim,S.K. and Wijesekara,I. (2010): Development and biological activities of marine-derived bioactive peptides: a review. J. Funct. Foods, 2:1-9.

Kumar, V. ; Kumar, K. ; Raman, R. P. ; Prasad, K.P. ; Roy, S. ; Kumar, S. and Kumar, N. (2014): Haematological and histopathological changes during carrageenan induced acute inflammatory response in labeorohita (Hamilton, 1822) fingerlings. Int. J. Curr. Microbiol. App. Sci., 3(7): 794-802.

Kushak, R.I. ; Drapeau,C. ; Em,V.C. and Winter, H.H. (2000): Favorable effects of bluegreen algae Aphanizomenon flos-aquae on rat plasma lipids. J. Am. Nutracu. Associ., 2(30): 59-65.

Ma,N.; Li,Y.; Li,X. and Wu,Y. (2013): Antiinflammatory effects of 4-methycyclo pentadecanone on edema models in mice. Int. J. Mol. Sci., 14(12): 2398023992.

Mansilla,E. ; Marın,G. ; Drago,H. ; Sturla,F. ; Salas,E. and Gardiner,C. (2006): Blood stream cells phenotypically identical to human mesenchymal bone marrow stem cells circulate in large amounts under the influence of acute large skin damage: new evidence for their use in regenerative medicine. Transplant. Proc., 38(3):967-969.

Massimo,L. (1972): Role of daunomycin in the treatment of acute leukemia in children. J. Pharm. Pharmaco., 24: 89 - 102 .

Maxim,E.D.; Jung,S.; Schanzer,S.; Richter,H.; Kurth,E.; Thiede,G.; Meinke,M.C. and Lademann,J. (2015): Influence of the systemic application of blue-green Spirulina platensis algae on the cutaneous carotenoids and elastic fibers in vivo. Cosmetics, 2(3): 302-312.

Mazia,D.; Brewer,P.A. and Alfert,M. (1953): The cyto-chemical staining and measurement of protein with mercuric bromophenol blue. Biol. Bull., 104:57-67.

Mc-Kim, J.M. (2014): Food additive carrageenan part I: a critical review of carrageenan in vitro studies, potential pitfalls and implications for human health and safety. Crit. Rev. Toxicol., 44(3): 211243.

Nahin,R.L. ； Barnes,P.M. ； Stussman,B.J. and Bloom,B. (2009): Costs of complementary and alternative medicine (CAM) and frequency of visits to CAM practitioners. Natl. Health Stat. Rep., 30(8):1-14.

Ochube, G.E.; Hassan, A.Z.; Kudi, C.A.; Fadason, S.T.; Bada, A.A.; Emmanuel, E.G.;Usman, B.;Augustine, A.;Bappa, M.N. and James, A.A.(2017): Effect of Aphanizomenon flos-auae (Afa) on endogenous mesenchymal stem cells proliferation in African adult donkeys (Equus africanus) during fracture healing. Nov. Tech. Arthritis Bone Res., 1(3):1-5.

Paget,E. and Barnes,M. (1964): Interspecies dosage conversion scheme in evaluation of results and quantitative application in different species. Evaluat.Drug Activities Pharmacometric, 1: 160-162.

Patel,A.; Mishra,S.; Pawar,R. and Ghosh,P.K. (2005): Purification and characterization of C-phycocyanin from cyanobacterial species of marine and freshwater habitat. Protein Express Purif., 40:248-255.

Pears, A. (1977): Histochemistry Theoretical, and Applied. $3^{\text {rd }}$ ed., Vol. 1. Churchill Livingstone, London.

Plaza, M. ; Herrero, M. ; Cifuentes, A. and Ibanez, E. (2009): Innovative natural functional ingredients from microalgae. J. Agricul. Food Chem., 57(16): 7159-7170.

Priya,K.S.; Arumugam,G.; Rathinam,B.; Wells,A. and Babu, M. (2004): Celosia argentea linn leaf extract improves wound healing in a rat burn wound model. Wound Repair Regen., 12:618-625.

Pugh,N. and Pasco,D.S.(2001): Characterization of human monocyte activation by a water soluble preparation of Aphanizomenon flos-aquae. Phytomedicine, 8: 445-453.

Pulawski,W. ;Ghoshdastider,U. ;Andrisano,V. and Filipek,S.

(2012): Ubiquitous amyloid. Applied Biochem. Biotechnol., 166 (7): 1626-1643. 
Radhakrishnan,R. ; Moore,S.A. and Sluka,K.A. (2003): Unilateral carrageenan injection into muscle or joint induces chronic bilateral hyperalgesia in rats. Pain, 104(3): 567577.

Regunathan,C. and Wesley,S.G. (2006): Pigment deficiency correction in shrimp broodstock using Spirulina as a carotenoid source. Aquacult. Nutr., $12: 425-432$.

Robertson,W.B. and Schwartz,B.(1953): Carrageenan : effects in animals. J. Biol. Chem., 201: 689 -696.

Romay,C.; Gonzalez,R.; Ledon,N.; Remirez,D.and R imbau, (2003): C-Phycocyanin: a biliprotein with antioxidant, antiinflammatory and neuroprotective effects. Current Protein and Peptide Sci., 4 (3): 207-216.

Schaap,A.; Rohrlack,T. and Bellouard,Y. (2012): Optical classification of algae species with a glass lab on a chip. Lab. Chip. J., 12:1527-1532.

Scoglio,S. ; Benedetti,Y. ; Benvenuti,F. ; Benedetti,S. and Benedetti,S. (2014): Selective monoamine oxidase $\mathrm{B}$ inhibition by an Aphanizomenon flos-aquae extract and by its constitutive active principles phycocyanin and mycosporine-like amino acids. Phytomedicine, 21(7):992997.

Scoglio,S.;Benedetti,S.;Canino,C.;Santagni,S.; Rattighieri,E.; Chierchia,E.; Canestrari,F. and Genazzani,A.D. (2009): Effects of a 2-month treatment with Klamin, a Klamath algae extract, on the general well-being, antioxidant profile and oxidative status of postmenopausal women. Gynecolog. Endocrinol., 25: 235-240.

Selmi,C. ; Leung,P.S. ; Fischer,L. ; German,B. ; Yang,C.Y. $\quad$; Kenny,T.P.; Cysewski,G.R. and Gershwin,M.E. (2011): The effects of Spirulina on anemia and immune function in senior citizens. Cell Mol. Immunol., 8:248254.

Sheehan,D. and Hrapchak,B. (1980): Theory and Practice of Histotechnology, $2^{\text {nd }}$ ed., Battelle Press, Ohio, p.282.

Singh,S.; Kate,B.N. and Banerjee,U.C. (2005): Bioactive compounds from cyanobacteria and microalgae: an overview. Crit. Rev. Biotechnol., 25:7395.

Snedecor,W.G. and Cochran,G.W. (1980): Statistical Method. $7^{\text {th }}$ edition, Iowa State University Press, Ames. Iowa. London.
Spolaore,P.; Joannis-Cassan,C.; Duran,E. and Isambert,A. (2006): Commercial applications of microalgae. J. Biosci. Bioengin., 101(2):87-96.

St-John,A.L.; Rathore,A.P. and Yap,H. (2011): Immune surveillance by mast cells during dengue infection promotes natural killer (NK) and NKT-cell recruitment and viral clearance. Proc. Natl. Acad. Sci.,108(22):9190-9195.

Valle,S. (1986): Special stains in microwave oven. J. Histotechnol., 9:237-248.

Vazquez,E.; Navarro,M.; Salazar,Y.; Crespo,G.; Bruges,G. ; Osorio,C.; Tortorici,V.; Vanegas,H. and López,M. (2015): Systemic changes following carrageenan- induced paw inflammation in rats. Inflamm. Res., 64(5):333-342.

Venkatesan,S.; Pugazhendy,K.;

Meenambal,M.; Sangeetha, D. ; asantharaja,C.V. ; Jayachandren,K. and Prabakaran,S. (2012): Protective role of Spirulina on the variation of haematological parameter induced by herbicide atrazine in the fresh water fish Cyprinus carpio (Linn). Int. J. Pharm. Biol. Arch., 3:249-254.

Vestola,J.; Shishido,T.K. and Jokela,J. (2014): Hassallidins, antifungal glycolipopeptides, are widespread among cyanobacteria and are the end-product of a nonribosomal pathway. Proc. Natl.Acad. Sci., 111: 1909-1917

Vinegar,R.; Truax,J.F.; Selph,J.L.; Johnston,P.R. ; Venable, A.L. and McKenzie,K.K. (1987): Pathway of carrageenan-induced inflammation in the limbs of rats. Federation Proceedings, 46(1):118-126.

Yang,Y.; Park,Y.; Cassada,D.A.; Snow,D.D.; Rogers,D.G. and Lee,J. (2011): In vitro and in vivo safety assessment of edible blue-green algae, Spirulina plantensis. Food Chem. Toxicol., 49(7):1560-1564.

Yang,Y.; Park,Y.; Cassada,D.A.; Snow,D.D.; Rogers,D.G. and Lee,J. (2011): In vitro and in vivo safety assessment of edible blue-green algae, Spirulina plantensis. Food Chem. Toxicol., 49(7):1560-1564.

Yogianti,F. ; Kunisada,M. ; Nakano,E.; Ono,R.; Sakumi,K.; Oka,S. ; Nakabeppu,Y. and Nishigori,C. (2014): Inhibitory effects of dietary Spirulina platensis on UVB-induced skin inflammatory responses and carcinogenesis. J. Invest. Dermatol., 134: 2610-2619. 